\title{
Hybridization of Castor Bean (Ricinus communis L.) in Morelos, México
}

\author{
Canul-Ku, Jaime ${ }^{1 *} ;$ Barrios-Gómez, Edwin J. ${ }^{1}$; Hernández-Meneses, Eleodoro ${ }^{2}$; Rangel-Estrada, Sandra E. ${ }^{1}$ \\ ${ }^{1}$ Instituto Nacional de Investigaciones Forestales, Agrícolas y Pecuarias. Campo Experimental \\ Zacatepec. Zacatepec, Morelos, México. C. P. 62780. ${ }^{2}$ Tecnológico Nacional de México Campus \\ Región Sierra. Francisco Javier Mina, Tabasco, México. C. P. 86801. \\ *Corresponding author: canul.jaime@inifap.gob.mx
}

\begin{abstract}
Objective: To determine the stigma receptivity and the pollen viability in order to make manual crosses and obtain viable progeny in castor bean (Ricinus communis L.).

Design/Methodology/Approach: Pollen viability tests were made on breeding materials by staining with acetocarmine solution. In elite materials, the receptivity of the stigma was evaluated with hydrogen peroxide. From the inflorescences, the male ones were removed and the female ones were preserved, which were covered with a glassine bag. After six days, they were checked and when they were considered receptive, manual pollinations were carried out between viable pollen materials and receptive stigma. The pollen of the male parent was impregnated in the stigmas and the inflorescence was covered again
\end{abstract}

Results: The breeding materials exhibited viable pollen since they were stained red. Whereas, the application of hydrogen peroxide to the stigmas of the elite materials showed bubbling, indicative that they were receptive. In 2014, 400 inflorescences were pollinated with 8 flowers on average and a fruit pollinated percentage of 61.21. In 2015, 245 inflorescences with 12 flowers on average and $61.24 \%$ of fruit were pollinated

Study Limitations/Implications: Temperature and relative humidity were fundamental factors for the success of castor bean fertilization.

Findings/Conclusions: The elite castor bean materials presented receptive stigmas and the improved viable pollen materials. Manual crosses produced fruits and seeds. The fruits pollinated were $61 \%$.

Keywords: Pollen viability, stigma receptivity, fruits pollinated, hybridization, genetic improvement.

\section{INTRODUCTION}

Whe irreversible exhaustion of oil reserves globally led to the search for alternative sources of renewable energies such as bioenergy. Biofuels in their solid, liquid and gas forms are currently of great importance, and therefore their study, production and use have intensified in the last 15 years (Guo et al., 2015). The search for new bioenergetics sources have centered on the production of ethanol and biodiesel from biomass of sugarcane 
(Saccharum spp. hybrids), maize (Zea mays L.) and grain sorghum (Sorghum bicolor L.). Advances have also been made in the research and technological development of other crops such as castor bean (Ricinus communis L.). Castor bean belongs to the Euphorbiaceae family, with chromosome number $2 n=2 x=20$. Their area of distribution is extensive worldwide, from tropical and subtropical regions to temperate zones (Lu et al., 2019). In Mexico, it is possible to find it throughout the country, and it is common for it to grow on the edges of paths and disturbed vegetation areas.

At the commercial scale, castor bean is cultivated in 1.5 million hectares in the world, where India, China, Brazil, Russia and Thailand stand out as main producers (Rukhsar et al., 2018). The oil from the seeds has chemical and physical properties that are unique and exceptional for industrial use (Lu et al., 2019; Rodrigues et al., 2019). In Brazil its cultivation is considered for family subsistence, interspersed with maize and bean, using local varieties with long cycles whose seed maturation is heterogeneous (Milani and Nóbrega, 2013).

In Mexico there are native populations of castor bean with wide morphological, productive, genetic and adaptive variability (Barrios-Gómez et al., 2018; GarcíaHerrera et al., 2019). However, the productive potential is limited because they are normally tall plants with abundant aerial biomass, lax bunches (sparse) of small size, sometimes indehiscent, with few fruits per bunch and seeds per fruit, and lower grain yield.

The commercial cultivation of castor bean in Mexico uses landrace and imported breeding materials. The landrace varieties are tall with low yield potential, but with tolerance to adverse factors, a useful trait to generate hybrid or improved varieties. These two groups of materials, together with the germplasm from native populations from Mexico, represent a valuable opportunity for genetic improvement of the species. Generating breeding materials that are adapted to particular production zones in Mexico require strategies that include the selection, mutagenesis, use of molecular markers and hybridization.

The success of hybridization in any plant species is sustained on understanding the moment when the stigmas are receptive and the time lapse when pollen grains are liberated during the day. In genetic improvement of cultivated species it is difficult to find two parents that originate a progeny with the highest amount of desirable traits (Ferreira et al., 2015). However, it should be considered that the quantitative traits of greatest economic importance are controlled by many pairs of genes.

The inflorescence of castor bean is a monoecious bunch with female flowers in the higher part and male in the lower part (Merkouropoulos et al., 2016). It is considered to be a crossed-pollination species (Ramesh et al., 2017) where wind is the main pollinating agent (Anjani et al., 2018). The liberation period of the pollen grains lasts 1 to 2 days, with optimal temperature conditions between 26 and $29{ }^{\circ} \mathrm{C}$ and relative humidity of $60 \%$. Meanwhile, the stigma is completely receptive for a period of 5 to 10 days depending on environmental conditions (Milani and Nóbrega, 2013). With the aim of establishing the bases of hybridization in castor bean in Mexico this study had the objectives of determining the receptivity of the stigma and viability of pollen, and making manual crosses to obtain viable progeny.

\section{MATERIALS AND METHODS}

This study was carried out in the Zacatepec Experimental Field of the National Institute for Forest, Agricultural and Livestock Research (Instituto Nacional de Investigaciones Forestales, Agrícolas y Pecuarias, INIFAP), located in the Zacatepec-Galeana Highway km 0.5 , on coordinates $18^{\circ} 39^{\prime} 16^{\prime \prime} \mathrm{LN}, 9^{\circ} 11^{\prime} 54.7^{\prime \prime} \mathrm{LW}$ and an altitude of $911.8 \mathrm{~m}$. The zone presents warm subhumid climate with summer rains (Aw0), where average annual precipitation is $800 \mathrm{~mm}$ and average annual temperature $24^{\circ} \mathrm{C}$ (Ornelas et al., 1997).

The genetic material used consisted of six elite materials of castor bean collected in many states of the country, which were selected for having greater size, weight and seed yield (Barrios et al., 2013), and three commercial varieties liberated by foreign seed companies. Receptivity tests were made on the stigma of elite materials, and pollen viability tests were applied on the breeding materials.

In 2014, pollen viability tests were made with the method proposed by Dempsey (1993), which consists in staining with acetocarmine (Meyer ${ }^{\circledR}$ coloring solution) and observing the change of color in the stereoscopic microscope. The stigma receptivity tests were applied following the method proposed by Osborn et al. (1988), which consists in placing a drop of hydrogen peroxide 
at 3\% on the stigmas; if bubbles are produced in the reaction then they are considered as receptive.

The genetic materials that resulted with viable pollen and receptive stigmas were used as parents to make manual crosses in November 2014 and October 2015. From the inflorescences, 10 female flowers were chosen that were in the same phenological state and the male flowers were eliminated (Figure 1a); then the inflorescence was covered with a glassine bag. The state of development of the stigmas was checked six days later and, when they were considered receptive, manual pollination impregnating the male parent's pollen on the stigmas was done; then the inflorescence was covered again (Figure 1b). Pollination was carried out from 9:20 a.m. to 11:30 a.m. in 2014 and from 10:00 a.m. to 1:30 p.m. in 2015. In the Zacatepec Experimental Field, in Morelos, the values of mean maximum, mean minimum, and mean daytime temperatures were 30.8, 15.9 and 27.4 ${ }^{\circ} \mathrm{C}$ in October and $30.8,12.1$ and $26.7^{\circ} \mathrm{C}$ in November, respectively. The monthly average precipitation was $67.2 \mathrm{~mm}$ in October and $10.4 \mathrm{~mm}$ in November. These means come from records that cover from 1961 to 2003 (Díaz et al., 2008). For each cross the variables that were found were the number of pollinized flowers, number of harvested fruits, and percentage of fruit pollinated.

\section{RESULTS AND DISCUSSION}

In the pollen viability tests in breeding materials, pollen grains stained with red color were observed, which indicated that they were viable so they could be used as male parents. Likewise, the application of hydrogen peroxide to the stigmas of the elite materials showed bubbling, indicative that they are receptive (Figure $1 \mathrm{c}$ ). The results of pollen viability and stigma receptivity indicated that the environmental conditions in the zone were optimal to carry out the pollination and later fertilization. Studies about the determination of pollen viability and stigma receptivity are essential activities to carry out genetic recombination. These tests have been useful in hybridization processes in species of the Echeveria genus (Rodríguez-Rojas et al., 2015) and in poinsettia (Euphorbia pulcherrima Willd. ex Klotszch) (Canul-Ku et al., 2015; Rodríguez et al., 2017).

In the year 2014, 400 inflorescences were pollinized, with 8 flowers on average each and fruit pollinated was $61.21 \%$. In 2015, 245 inflorescences were pollinized, with 12 flowers on average and fruit pollinated of $61.24 \%$ (Figure 1d).
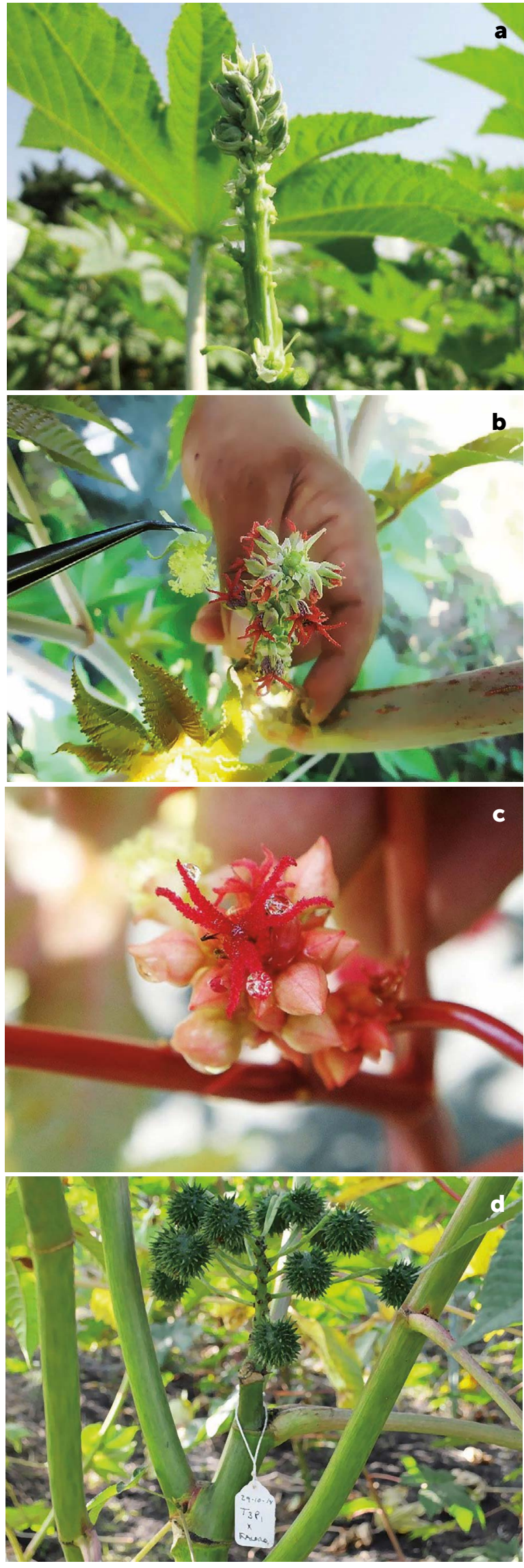

Figure 1. Hybridization process in castor. a) Emasculated inflorescence. b) Manual pollination. c) Receptive stigma. d) Fruit development 
In the evaluation of the behavior of fruit pollinated in function of the time of pollination in 2014, it was observed that the highest percentage was obtained from pollinized flowers at 9:20 in the morning and the lowest at 10:30 (Figure 2). These results show that the minimal differences of time to do the manual pollinations are dependent on climate conditions.

In the year 2015 the pollinations performed at 10:20 in the morning presented the lowest percentage of fruit pollinated with $33 \%$ and at 12:30 the highest with $77 \%$. In that year, the lowest fruit pollinated was during the period of 10:20 to 10:50 (Figure 3).

The best behavior of fruit pollination was obtained in 2014 (Figure 2). The next year increases and decreases were observed during the pollination period (Figure 3). This response is probably due to the environmental conditions that were present. Historical data show that the mean daytime temperature in the Zacatepec Experimental Field is 26.7 to $27.4{ }^{\circ} \mathrm{C}$ (Díaz et al., 2008) during the time period when the pollinations were performed. If it considered that pollen grains from castor bean are liberated in optimal conditions of temperature between 26 and $29^{\circ} \mathrm{C}$ for 1 to 2 days and the stigma is completely receptive 5 to 10 days (Milani and Nóbrega, 2013), it is deduced that the environmental conditions of the zone favored fertilization.

In the pollination of five species from the Echeveria genus, $100 \%$ of fruit pollinated was obtained, although the viable seeds only formed in intra and interspecific crossed pollination (Rodríguez-Rojas et al., 2015). In

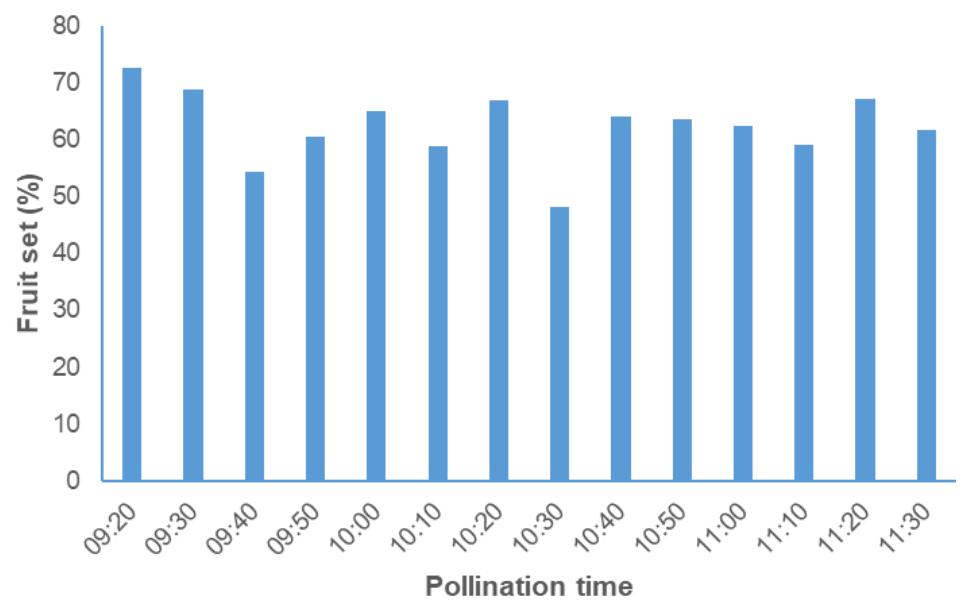

Figure 2. Percentage of fruit set as a function of pollination time. Zacatepec Experimental Field. 2014.

poinsettia it was reported that fruit pollinated is $68 \%$ with the technique of modified emasculation and it is crucial for hybrid generation. The process consists in cutting two thirds of the bract from the apex to the base of the inflorescence, eliminating male flowers, leaving between three and five non-receptive female flowers with the same phenological state covered with a waxed bag (Canul-Ku et al., 2015).

The knowledge generated about pollen viability, stigma receptivity and fruit pollinated in these castor bean materials establish the bases that will allow generating genetic variants. With this information it would be possible to undertake the genetic improvement of castor bean and to obtain varieties and hybrids for specific environmental conditions in Mexico. The main goal of this genetic improvement will be to reduce the varietal dependency on imported breeding material.

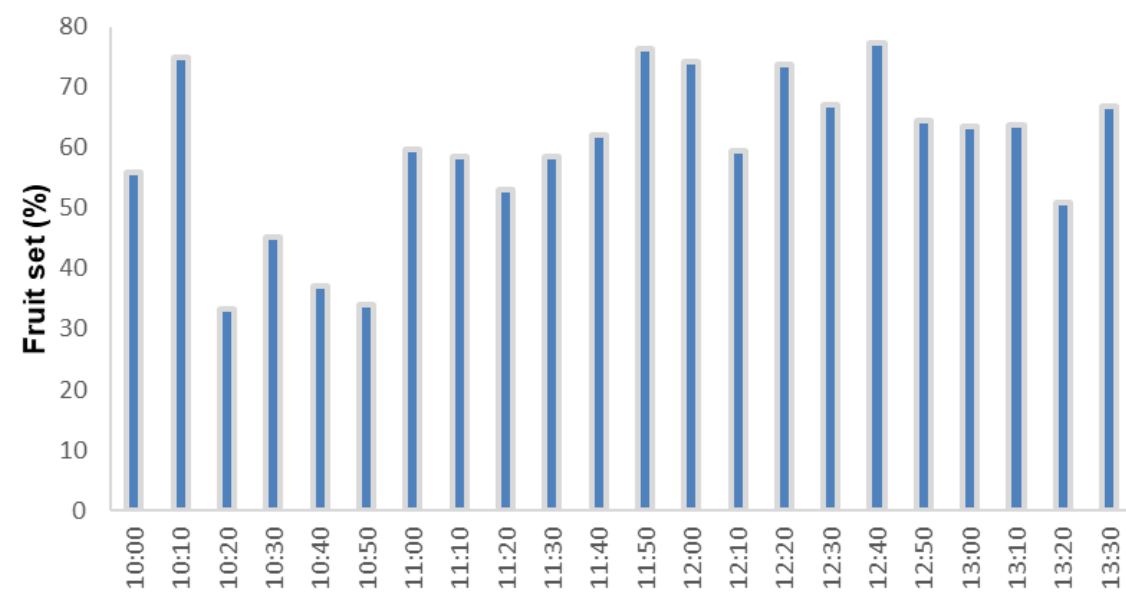

Pollination time

Figure 3. Percentage of fruit set as a function of pollination time. Zacatepec Experimental Field. 2015

\section{CONCLUSIONS}

The elite materials of castor bean presented receptive stigmas and the breeding materials viable pollen. Manual crosses produced fruits and seeds. Fruit pollination was $61 \%$. This indicates that there is genetic potential to generate new combinations through hybridization in castor bean.

\section{ACKNOWLEDGEMENTS}

The authors thoroughly thank INIFAP for the economic support granted to research projects, validation and transference of technology, which made this scientific contribution possible. 


\section{REFERENCES}

Anjani, K., Raoof, M. A., Prasad, M., Duraimurugan, P., Lucose, C., Yadav, P., Prasad, R. D., Lal, J., Sarada, C. (2018) Trait-specific accesions in global castor (Ricinus communis L.) germplasm core set for utilization in castor improvement. Industrial Crops and Products 112: 766-774.

Barrios, G. E., Zamarripa, C. A., Canul, K. J., Hernández, A. M., Alarcón, C. N., Chepetla, C. V. (2013). Evaluación de materiales élite de higuerilla (Ricinus communis L.) en Morelos. Ciencia y Tecnología Agropecuaria de México 1(2): 27-32.

Barrios-Gómez, E. J., Canul-Ku, J., Hernández-Arenas, M., Solís-Bonilla, J. L. (2018). Evaluación de dos ciclos de higuerilla en Morelos, México: siembra y rebrote. Revista Mexicana de Ciencias Agrícolas 9(8): 16631673.

Canul-Ku, J., García-Pérez, F., Barrios-Gómez, E. J., Campos-Bravo, E., Osuna-Canizalez, F., Ramírez-Rojas, S. G., Rangel-Estrada, S. E. (2015). Técnica para producir híbridos en nochebuena (Euphorbia pulcherrima Willd. ex Klotszch). Agroproductividad 8:32-37.

Díaz, G. P., Serrano, A. V., Ruiz, C. J., Ambriz, C. R., Cano, G. M. (2008). Estadísticas climatológicas básicas del estado de Morelos, período 1961-2003. INIFAP, CIRPAS, Campo Experimental Zacatepec. Libro Técnico Número 3. 153 p.

Dempsey, E. (1993). Traditional analysis of maize pachytene chromosomes. pp. 432 - 441. En: Freeling, M; Walbot, V. (eds.) The Maize Handbook. New York: Springer.

Ferreira, A. A., Menesez, J. J., Silva, V. M., Souza, C. J., Souza, C. P., Ferreira, A. A. (2015). Genetic progress and potential of common bean families obtained by recurrent selection. Crop Breeding and Applied Biotechnology 15: 218-226

García-Herrera, E. J., Olivares-Ramírez, A., Amante-Orozco, A., Hernández-Ríos, I., Rössel-Kipping, E. D., Pimentel-López, J., Delgadillo-Ruiz, O., Gómez-González, A. (2019). Evaluación de colectas de higuerilla (Ricinus communis L.) del Altiplano centro-norte de México. Agroproductividad 12(1): 25-31.

Guo, M., Song, W., Buhain, J. (2015). Bioenergy and biofuels: history, status, and perspective. Renewable and Sustainable Energy Reviews 42: 712-725.

Lu, J., Shi, Y., Yin, X., Liu, S., Liu, C., Wen, D., Li, W., He, X, Yang, T. (2019). The genetic mechanism of sex type, a complex quantitative trait, in Ricinus communis L. Industrial Crops and Products 128: 590-598.

Merkouropoulos, G., Kapazoglou, A., Drosou, V., Jacobs, E., Krolzig, A., Papadopoulus, C., Hilioti, Z. (2016). Dwarf hybrids of the bioenergy crop Ricinus communis suitable for mechanized harvesting reveal differences in morpho-physiological characteristics and seed metabolic profiles. Euphytica 210: 207-219.

Milani, M., Nóbrega, M. B. (2013). Castor breeding. pp. 239-254. En: Sven Bode Andersen (ed.). Plant Breeding from Laboratories to Fields.

Ornelas, R. F., Ambriz, C. R., Bustamante, O. J. (1997). Delimitación y definición de agrohábitats en el estado de Morelos. Instituto Nacional de Investigaciones Forestales, Agrícolas y Pecuarias. Publicación especial Número 11. 19 p.

Osborn M., P. Kevan and A. Meredith. (1998). Pollination biology of Opuntia polycantha and Opuntia phaeacantha (Cactaceae) in Sourther Colorado. Plant Systematics and Evolution 159: 139-144.

Ramesh, M., Lavanya, C., Sujatha, M., Bhave, M. H., Aruna, J. (2017). Inheritance of morphological characters and sex expression in castor (Ricinus communis L.). Journal of Oilseeds Research 34: 247-250.

Rodrigues, S. A., Alves, S. S., Araujo, S. L., Souza, D., Araujo, G., Loyola, D. J., Silva, L. E., Loyola, D. A. (2019). Characterization and performance of castor bean lineages and parents at the UFRB germplasm bank. PLOS ONE 14(1): e0209335.

Rodríguez-Rojas, T., Andrade-Rodríguez, M., Canul-Ku, J., Castillo-Gutiérrez, A., Martínez-Fernández, E., GuillénSánchez, D. (2015). Viabilidad de polen, receptividad del estigma y tipo de polinización en cinco especies Echeveria en condiciones de invernadero. Revista Mexicana de Ciencias Agrícolas 6(1): 111-123.

Rodríguez, R. T., Andrade-Rodríguez, M., Villegas-Torres, O., Castillo-Gutiérrez, A., Colinas-León, M., Avitia-García, E., Alia-Tejacal, I. (2017). Características reproductivas de nueve variedades de nochebuena (Euphorbia pulcherrima Willd. ex Klotzsch). Revista Mexicana de Ciencias Agrícolas 8: 295-306.

Rukhsar, S., Patel, M. P., Parmar, D. J. (2018). Genetic variability, character association and genetic divergence studies in castor (Ricinus communis L.). Annals of Agrarian Science 16: 143-148. 